\title{
Textural, surface, thermal and sorption properties of the functionalized activated carbons and carbon nanotubes
}

\author{
Piotr Nowicki", Wiktor Szymanowski, Robert Pietrzak \\ Adam Mickiewicz University in Poznań, Faculty of Chemistry, Laboratory of Applied Chemistry, Umultowska 89b, \\ 61-614 Poznań, Poland \\ "Corresponding author: e-mail: piotrnow@amu.edu.pl
}

\begin{abstract}
Two series of functionalised carbonaceous adsorbents were prepared by means of oxidation and nitrogenation of commercially available activated carbon and multi-walled carbon nanotubes. The effect of nitrogen and oxygen incorporation on the textural, surface, thermal and sorption properties of the adsorbents prepared was tested. The materials were characterized by elemental analysis, low-temperature nitrogen sorption, thermogravimetric study and determination of the surface oxygen groups content. Sorptive properties of the materials obtained were characterized by the adsorption of methylene and alkali blue 6B as well as copper(II) ions. The final products were nitrogen- and oxygen-enriched mesoporous adsorbents of medium-developed surface area, showing highly diverse $\mathrm{N}$ and O-heteroatom contents and acidic-basic character of the surface. The results obtained in our study have proved that through a suitable choice of the modification procedure of commercial adsorbents it is possible to produce materials with high sorption capacity towards organic dyes as well as copper(II) ions.
\end{abstract}

Keywords: carbonaceous adsorbents, oxidation; nitrogenation, surface functional groups, thermogravimetric study, adsorption from liquid phase.

\section{INTRODUCTION}

Adsorption processes are widely applied in many branches of industry, both in technologically developed and developing countries. Thus, it is understood that the search for new, more selective and effective adsorbents and optimisation of those already known have been of continuous interest all over the world. Much attention is paid to the search for new precursors of adsorbents, in particular new precursors of activated carbon adsorbents, which is evidenced by a large number of papers whose authors have been testing all kinds of industrial and agricultural waste products ${ }^{1-8}$. Also much interest has been paid to the effects of different modifications of adsorbents, both used on laboratory and industrial scale. The modification is usually realised as functionalization of the adsorbent surface with various functional groups (organic and inorganic). Then, the effects of such modification on the textural parameters, thermal stability and mechanical strength are optimised ${ }^{9-13}$.

Although the effects of introduction of heteroatoms (e.g. O, N, S, P, Cl, F) or metal ions (e.g. Pt, Ag, Au, V, $\mathrm{Fe}$ ) into the structure of adsorbents have been reported in many papers ${ }^{14-20}$, there is still much to be learnt in the field and the problems are still of interest for many research groups, including our group. Earlier ${ }^{21-23}$ we have studied the effect of nitrogen and oxygen functional groups on the acid-base properties, porous structure and sorption ability from gas phase of the activated carbons of our interest. Results of our studies have shown beneficial effect of such modifications, which prompted the attempts at modification of commercial products.

The main aim of this study was to obtain and characterise new carbonaceous adsorbents obtained by introduction of nitrogen and oxygen functional groups into the structure of commercially available activated carbon and multi-walled carbon nanotubes. The suitability of these new materials as adsorbents of organic dyes and copper(II) ions from liquid phase was also tested.

\section{EXPERIMENTAL}

\section{Material}

The investigation presented in this work was carried out on commercial micro/mesoporous activated carbon - Norit ${ }^{\circledR}$ SX2 (denoted as AC) and multi-walled carbon nanotubes (O.D. $\times$ L 6-9 $\mathrm{nm} \times 5 \mu \mathrm{m},>95 \%$ C, SigmaAldrich $^{\circledR}$, denoted as NT. The starting materials were subjected to three different treatments: (1) oxidation with $20 \% \mathrm{HNO}_{3}(\mathrm{OX}),(2)$ reaction with urea (U) and (3) oxidation followed by reaction with urea (OXU), as presented in Scheme 1. These modifications were performed according to the procedures described below.

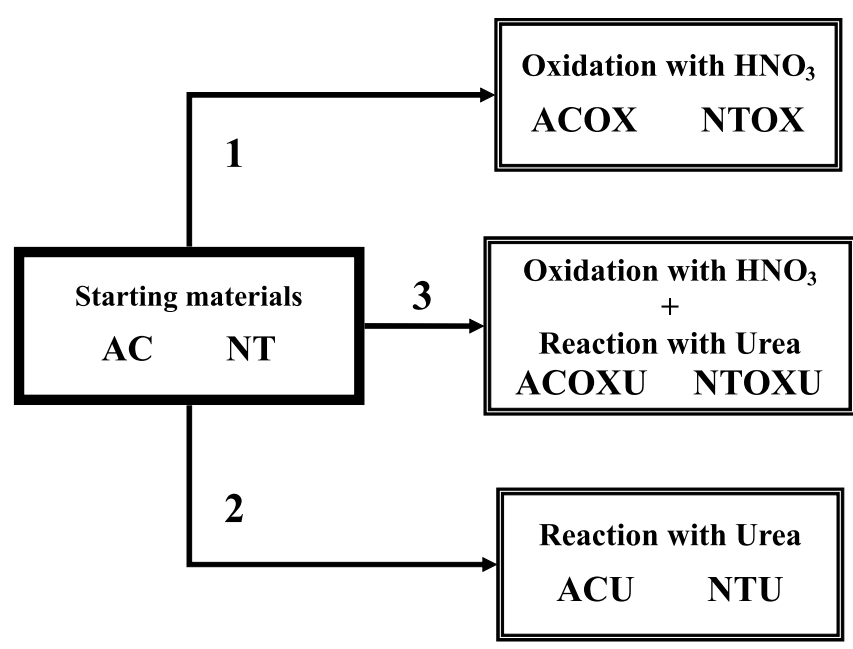

Scheme 1. Preparation of modified activated carbons and carbon nanotubes

\section{Oxidation with $20 \%$ solution of $\mathrm{HNO}_{3}$}

Portions of $10 \mathrm{~g}$ of activated carbon or carbon nanotubes were placed in two-necked flask, equipped with a reflux condenser and dropping funnel. Next, $150 \mathrm{ml}$ of $20 \% \mathrm{HNO}_{3}$ was added and the reaction mixture was heated up to boiling point. After that, the remaining portion of the acid $(150 \mathrm{ml})$ was slowly added to the flask. 
After addition of the last portion of $\mathrm{HNO}_{3}$, the reaction was continued for $3 \mathrm{~h}$. The final product was recovered by filtration, washed repeatedly with deionized water (until the $\mathrm{pH}$ of the effluent water was constant) and dried at $110^{\circ} \mathrm{C}$ (samples ACOX and NTOX, respectively).

\section{Reaction with urea at high temperature}

Portions of $10 \mathrm{~g}$ of carbonaceous materials were impregnated with urea at the weight ratio of 1:1, dried at $110^{\circ} \mathrm{C}$ to constant mass and then subjected to thermal treatment at $350^{\circ} \mathrm{C}$, for $3 \mathrm{~h}$, in air flow $(100 \mathrm{ml} / \mathrm{min})$. The nitrogen-enriched materials were washed with hot deionized water in order to remove the unreacted part of urea and dried at $110^{\circ} \mathrm{C}$. Incorporation of nitrogen was applied to starting activated carbon (ACU) and nanotubes (NTU) as well as to products of their oxidation (ACOXU and NTOXU samples).

\section{Samples characterization}

The elemental analysis of the all samples under investigation was performed on an Elementar Analysensysteme instrument, model Vario EL III. The textural characterisation of the samples was based on the nitrogen-adsorption isotherms determined at $-196^{\circ} \mathrm{C}$ with a Quantachrome Autosorb iQ surface area analyser. Before the isotherm measurements the samples were outgassed at $150^{\circ} \mathrm{C}$ for $8 \mathrm{~h}$. Surface area and pore size distribution were calculated by BET (Brunauer-Emmett-Teller) and BJH (Barrett-Joyner-Halenda) methods, respectively. Average pore diameter and total pore volume were determined as well. Additionally, micropores surface area and volume were calculated using t-plot method. The content of surface functional groups of acidic and basic character was determined by the Boehm method ${ }^{24}$, whereas the $\mathrm{pH}$ of the materials was evaluated using the procedure described in detail in our previous study ${ }^{25}$. Thermogravimetric analysis was performed on an SETSYS 12 made by Setaram, according to the procedure described earlier ${ }^{26}$.

\section{Adsorption tests}

Determination of the adsorption of methylene blue, alkali blue $6 \mathrm{~B}$ and copper(II) ions was performed using the following procedure: samples of the prepared adsorbents of equal masses of $0.2 \mathrm{~g}$ were added to $100 \mathrm{ml}$ of appropriate adsorbate solution with initial concentrations of $1000 \mathrm{mg} / \mathrm{l}$ and the suspension was stirred for $24 \mathrm{~h}$ to reach equilibrium. The concentrations of organic dyes as well as copper(II) ions in the solution after adsorption were determined using a double beam UV-Visible spectrophotometer (Cary Bio 100, Varian) at 660, 593 and $620 \mathrm{~nm}$ wavelength, respectively.

\section{RESULTS AND DISCUSSION}

\section{Elemental composition of adsorbents prepared}

The chemical compositions of the starting and modified samples are given in Table 1.

As follows from these data, each of the modifications performed resulted in significant changes in the content of mineral substances (ash) and in the contribution of particular elements in the carbon structure. The character of the changes depends on the variant of modification and on the type of material subjected to the thermo-chemical treatment. Oxidation with $20 \% \mathrm{HNO}_{3}$ leads not only to introduction of significant amounts of oxygen into the adsorbent structure, but also to a considerable increase in the content of ash and to small changes in the contribution of the other heteroatoms, nitrogen and hydrogen. Introduction of the oxygen functional groups is accompanied by a significant decrease in the content of carbon, particularly pronounced for the activated carbon ACOX. Exposure of the activated carbon ACOX and multi-walled nanotubes NTOX to urea under oxidising conditions results in the introduction of significant amount of nitrogen in their structures and rather insignificant changes in the contents of the other elements. The activated carbon sample proved much more susceptible to modification, as the content of nitrogen in ACOXU was $9.1 \mathrm{wt} \%$ which was almost twice greater than in NTOXU modified in the same way which was $4.7 \mathrm{wt} \% \mathrm{~N}^{\text {daf }}$. The greater reactivity of activated carbon is also indicated by a different character of changes in the content of oxygen as a result of the reaction with urea. The content of $\mathrm{O}^{\mathrm{daf}}$ in NTOXU is by $1.7 \mathrm{wt} \%$ lower than in NTOX, while ACOXU shows a small increase in the content of oxygen with respect to that in ACOX.

The decrease in the content of $\mathrm{O}^{\text {daf }}$ in nanotubes can be a consequence of the fact that part of oxygen groups was engaged in oxygen-nitrogen connections as it has been established ${ }^{21}$, 27, that the presence of oxygen functional groups on the surface of carbon favours incorporation of nitrogen groups. As the structure of nanotubes is less susceptible to modification than that of activated carbon, the conditions used for the reaction with urea (temp. $350^{\circ} \mathrm{C}$, air atmosphere) could be too mild to lead to further oxidation of their surface. This supposition is to some degree confirmed by changes in the content of oxygen in the samples ACU and NTU subjected exclusively to the reaction with urea. According to our results, the content of oxygen in NTU is at the same level as in the initial nanotubes material NT, while the content of oxygen in $\mathrm{ACU}$ is by about $1 \%$ greater than

Table 1. Elemental composition of adsorbents prepared [wt \%]

\begin{tabular}{|c|c|c|c|c|c|c|}
\hline Sample & Ash & $\mathrm{C}^{\text {daf* }}$ & $\mathrm{H}^{\text {daf }}$ & $\mathrm{N}^{\text {daf }}$ & $\mathrm{S}^{\text {daf }}$ & $\mathrm{O}^{\text {daf }}{ }^{* *}$ \\
\hline$A C$ & 7.6 & 94.9 & 0.5 & 0.5 & 0.1 & 4.0 \\
\hline ACOX & 8.2 & 80.0 & 1.1 & 1.0 & 0.1 & 17.8 \\
\hline ACOXU & 6.7 & 71.2 & 1.2 & 9.1 & 0.1 & 18.4 \\
\hline NT & 0.2 & 98.0 & 0.1 & 0.1 & 0.0 & 1.8 \\
\hline NTOX & 0.3 & 94.0 & 0.3 & 0.2 & 0.0 & 5.5 \\
\hline NTOXU & 0.8 & 91.1 & 0.4 & 4.7 & 0.0 & 3.8 \\
\hline
\end{tabular}

"daf - dry-ash-free, " from difference. 
in $\mathrm{AC}$, which points to a small oxidation of the activated carbon upon the reaction of urea.

The materials obtained as a result of the reaction with urea ACU and NTU have a lower content of nitrogen (nanotubes almost twice lower) than the oxidised samples treated with urea ACOXU and NTOXU, which confirms the earlier reports of a beneficial effect of the oxygen functional groups on the efficiency of nitrogenation of carbon materials.

\section{Textural structure of adsorbents prepared}

The three variants of thermo-chemical treatment were applied to activated carbon and nanotubes to provoke not only chemical but also textural changes. As follows from the data collected in Table 2, the initial materials show much pronounced textural differences.

The multi-walled carbon nanotubes show not much developed surface area $\left(271 \mathrm{~m}^{2} / \mathrm{g}\right)$ and remarkably mesoporous structure, while the activated carbon used has twice larger surface area $S_{\mathrm{BET}}$ and a considerable contribution of micropores and mesopores of small diameter, as its mean pore diameter is $5.02 \mathrm{~nm}$. Each of the modifications applied brings about significant changes in the textural parameters of both materials, but the scale of changes is much greater in the samples obtained from activated carbon ACOX, ACOXU and ACU.

Modifications of nanotubes lead to an insignificant change in their surface area, by $34-49 \mathrm{~m}^{2} / \mathrm{g}$, while the same modifications of activated carbon cause a drastic decrease in its surface area, from $136 \mathrm{~m}^{2} / \mathrm{g}$ for ACOX to $328 \mathrm{~m}^{2} / \mathrm{g}$ for ACU. The decrease in the surface area is accompanied by a significant decrease in the micropores area, while the change in the area of external surface is much smaller. The modifications by oxidation and enrichment in nitrogen lead also to a considerable decrease in the total pore volume. It is particularly pronounced for nanotubes whose total pore volume becomes about twice smaller than that of the initial samples. A similarly drastic decrease also takes place in the mean pore diameter; the mean pore diameter in the modified nanotubes is by 1.73-2.49 nm smaller than that of the unmodified material. For ACOX and ACOXU a decrease in the mean pore size is also observed but it is much smaller, by $0.48-0.73$ nm. For ACU (activated carbon subjected to the reaction with urea only) the mean pore diameter increased by $1.51 \mathrm{~nm}$. It is most probably related to the fact that in ACOX and ACOXU the contribution of micropores slightly increased as a result of modifications, while ACU shows almost twice smaller $V_{m} / V_{t}$, ratio than the initial material AC. So pronounced changes in the total pore volume and pore diameter are most probably caused by blocking of some part of pores by the nitrogen and oxygen functional groups introduced upon modification ${ }^{22}$. Different character of the changes caused by different modifications suggests that in the process of oxidation more important are the pores of greater diameters and inside them the majority of carbon-oxygen connections are generated, whereas in the reaction with urea more important are smaller pores. However, verification of this supposition needs further studies.

The mesoporous character of the initial materials and the adsorbents obtained by their modification has been confirmed by the shapes of the adsorption/desorption isotherms presented in Figures 1-2.

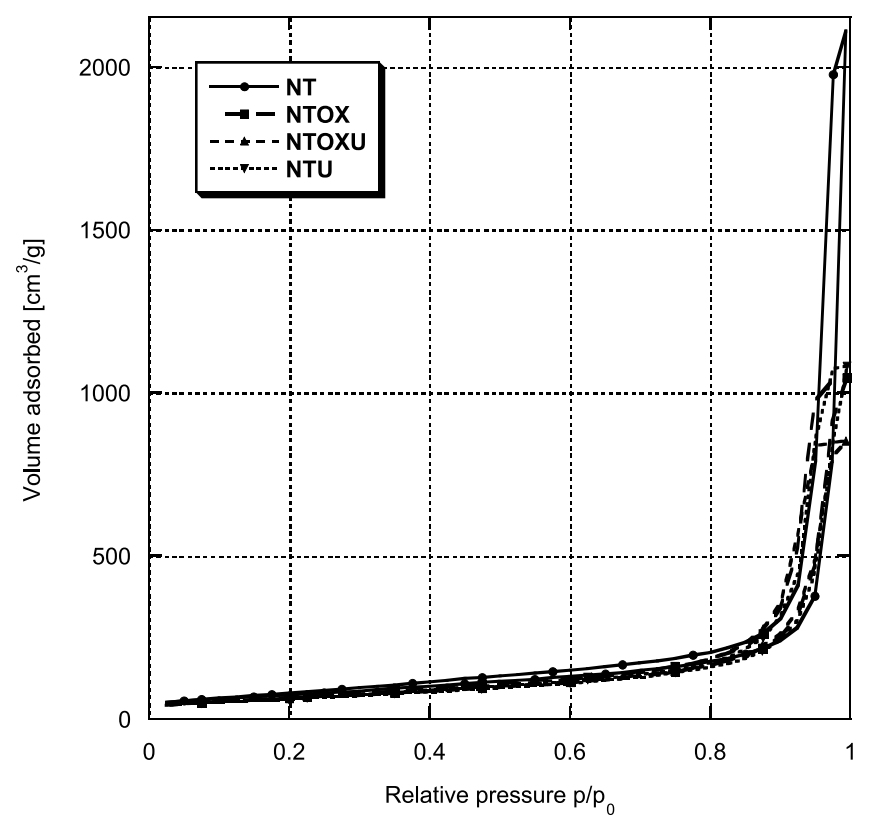

Figure 1. Nitrogen adsorption isotherms of the activated carbons

According to the IUPAC classification, the carbon nanotubes show type IV isotherm (Fig. 1), characteristic of solid state materials on which the adsorption proceeds via multilayer adsorption followed by capillary condensation $^{28}$. The activated carbon isotherm is close to type I, (Fig. 2), characteristic of microporous materials and mesoporous materials with pore size close to the micropores range. The isotherms show clear hysteresis loops. For carbon nanotubes the hysteresis loop is close to $\mathrm{H} 1$ type, characteristic of materials with cylindrical pore geometry and high degree of pore size uniformity, while for activated carbon the hysteresis loop looks like H3 type, characteristic of materials with slit-like pores.

Table 2. Textural parameters of adsorbents prepared

\begin{tabular}{|l|c|c|c|c|c|c|c|}
\hline \multirow{2}{*}{ Sample } & \multicolumn{3}{|c|}{$\begin{array}{c}\text { Surface area } \\
{\left[\mathrm{m}^{2} / \mathrm{g}\right]}\end{array}$} & \multicolumn{2}{c|}{$\begin{array}{c}\text { Pore volume } \\
{\left[\mathrm{cm}^{3} / \mathrm{g}\right]}\end{array}$} & \multirow{2}{*}{$\mathrm{V}_{\text {mic }} / \mathrm{V}_{\text {tot }}$} & \multirow{2}{*}{ Average pore diameter [nm] } \\
\cline { 2 - 6 } & total & micropores & external & total & micropores & & \\
\hline AC & 618 & 410 & 208 & 0.77 & 0.23 & 0.29 & 5.02 \\
\hline ACOX & 482 & 302 & 180 & 0.52 & 0.16 & 0.31 & 4.29 \\
\hline ACOXU & 454 & 296 & 158 & 0.51 & 0.16 & 0.32 & 4.53 \\
\hline ACU & 290 & 129 & 160 & 0.47 & 0.07 & 0.15 & 6.53 \\
\hline NT & 271 & - & 266 & 3.27 & - & - & 4.83 \\
\hline NTOX & 237 & - & 237 & 1.62 & - & - & 2.34 \\
\hline NTOXU & 226 & - & 226 & 1.32 & - & - & 2.73 \\
\hline NTU & 222 & - & 222 & 1.67 & - & - & 3.10 \\
\hline
\end{tabular}

$\mathrm{V}_{\text {mic }} / \mathrm{V}_{\text {tot }}$ - micropores contribution. 


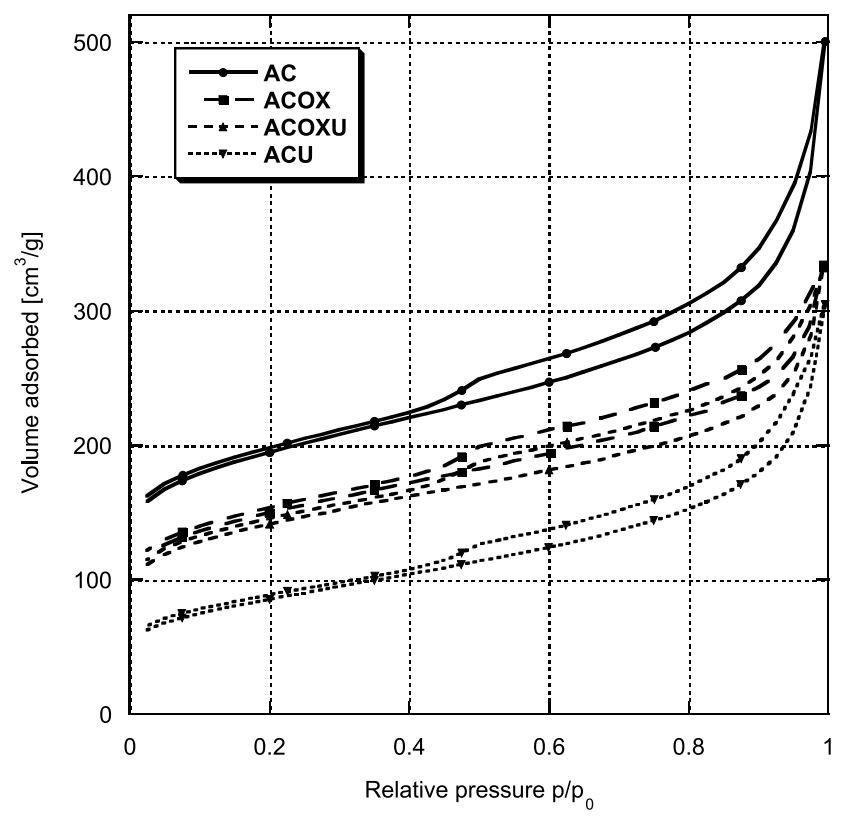

Figure 2. Nitrogen adsorption isotherms of the carbon nanotubes

\section{Acid-base properties of adsorbents prepared}

As follows from the data presented in Table 3, the carbon materials differ significantly in the number of acid and basic functional groups and in the surface $\mathrm{pH}$.

As far as nanotubes are concerned, the modifications lead to insignificant changes in $\mathrm{pH}$, from weakly acidic for NTOX to weakly basic for NTU. The lowest $\mathrm{pH}$ for NTOX is related to the presence of considerable amounts of acidic oxygen functional groups forming as a result of exposure to $\mathrm{HNO}_{3}$. NTOXU, which was oxidised and then subjected to enrichment in nitrogen, shows an intermediate acid-base character and its $\mathrm{pH}$ is slightly above 7 . A slightly basic character of NTU $(\mathrm{pH}$ 8.0) most probably follows from the domination of basic oxygen functional groups on the surface of this sample.

As to the activated carbon sample, its oxidation caused much greater changes in the acid-base surface character. ACOX surface showed acidic character of $\mathrm{pH} 4.6$ which was a consequence of introduction of much greater amount of acidic functional groups (up to $1.86 \mathrm{mmol} / \mathrm{g}$ ) than upon oxidation of nanotubes. The values of $\mathrm{pH}$ of the other samples obtained as a result of AC modification are similar to that of the initial carbon, but the content of acidic and basic groups on the surface of ACOXU and $\mathrm{ACU}$ is much greater than on the unmodified carbon.

\section{Thermal properties of adsorbents prepared}

Thermal properties of the samples studied were characterised by thermogravimetric measurements in the helium atmosphere. As follows from the character of TG and DTG curves, presented in Figures 3-4, the activated

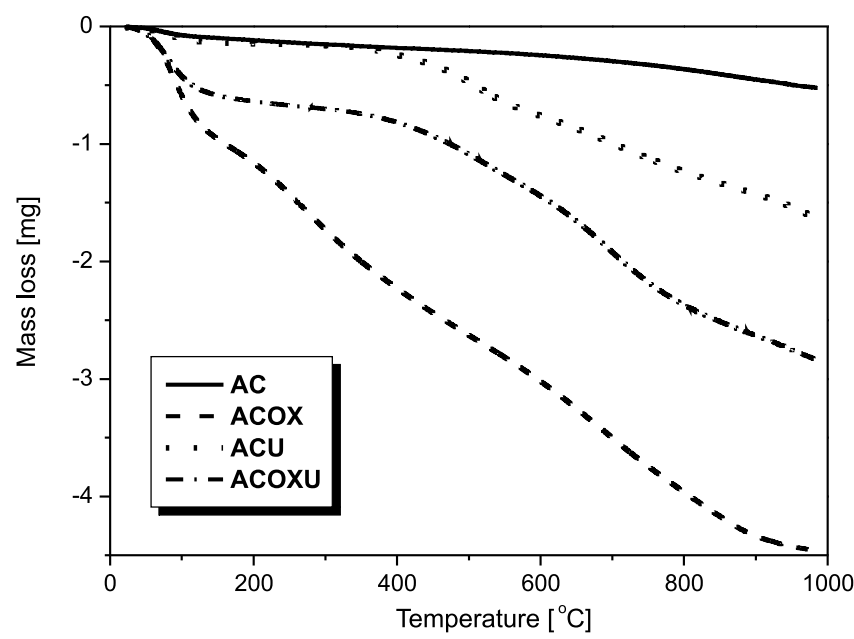

Figure 3. TG curves of the activated carbons

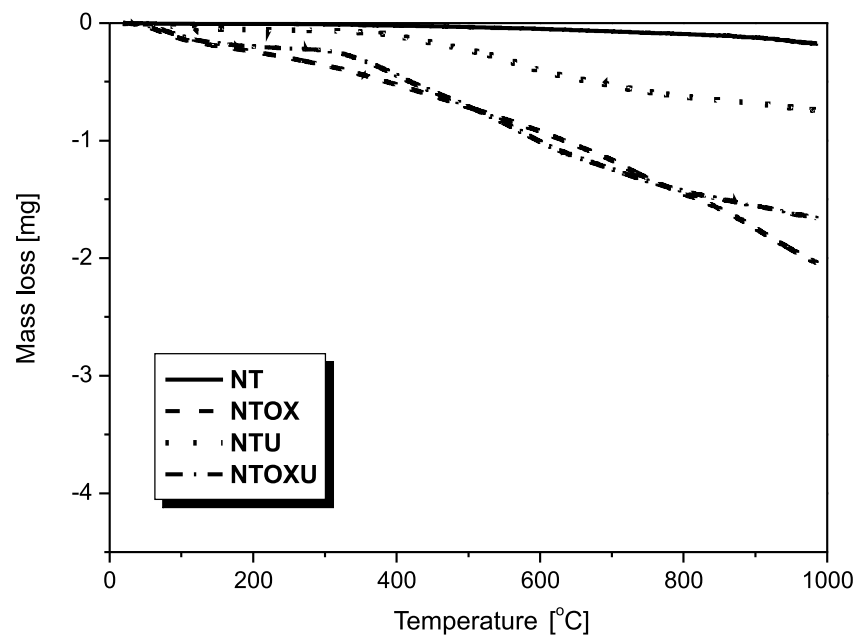

Figure 4. TG curves of the carbon nanotubes

carbon and carbon nanotubes are thermally stable up to about 400 and $800^{\circ} \mathrm{C}$, respectively.

Unfortunately, each modification affects the thermal stability of the materials studied and the changes are much more pronounced for the samples obtained from activated carbon. This observation confirms the earlier suppositions on greater reactivity and susceptibility to modification of activated carbon. The least thermally stable was ACOX, obtained by oxidation with $\mathrm{HNO}_{3}$, showing the first symptoms of thermal decomposition already above $200^{\circ} \mathrm{C}$. For NTOX also obtained by oxidation with $\mathrm{HNO}_{3}$, the loss of mass is over twice smaller, which confirms greater thermal stability of nanotubes. Thermal stability of the samples oxidised and exposed to urea, in particular ACOXU, is much higher. A possible explanation is that the rather unstable oxygen groups have been removed or underwent transformation in the process of enrichment in nitrogen, so the carbon

Table 3. Acid-base properties of adsorbents prepared

\begin{tabular}{|l|c|c|c|c|}
\hline Sample & $\mathrm{pH}$ & Acidic groups [mmol/g] & Basic groups [mmol/g] & Total content [mmol/g] \\
\hline AC & 7.6 & 0.26 & 0.37 & 0.63 \\
\hline ACOX & 4.6 & 2.12 & 0.78 & 2.90 \\
\hline ACOXU & 7.6 & 0.62 & 0.67 & 1.29 \\
\hline ACU & 7.7 & 0.53 & 0.81 & 1.34 \\
\hline NT & 6.7 & 0.12 & 0.06 & 0.18 \\
\hline NTOX & 6.2 & 0.56 & 0.25 & 0.81 \\
\hline NTOXU & 7.4 & 0.36 & 0.37 & 0.73 \\
\hline NTU & 8.0 & 0.12 & 0.25 & 0.37 \\
\hline
\end{tabular}


after such treatment was more thermally stable. The most thermally stable were ACU and NTU, subjected only to the reaction with urea. It may mean that some part of urea introduced upon the modification was built into the external graphene layers, which improved the thermal stability of these samples ${ }^{29}$.

The DTG curves of the samples studied (Figs. 5-6), except the initial nanotubes, show a characteristic minimum at $80-90^{\circ} \mathrm{C}$, corresponding to the desorption of physically adsorbed water.

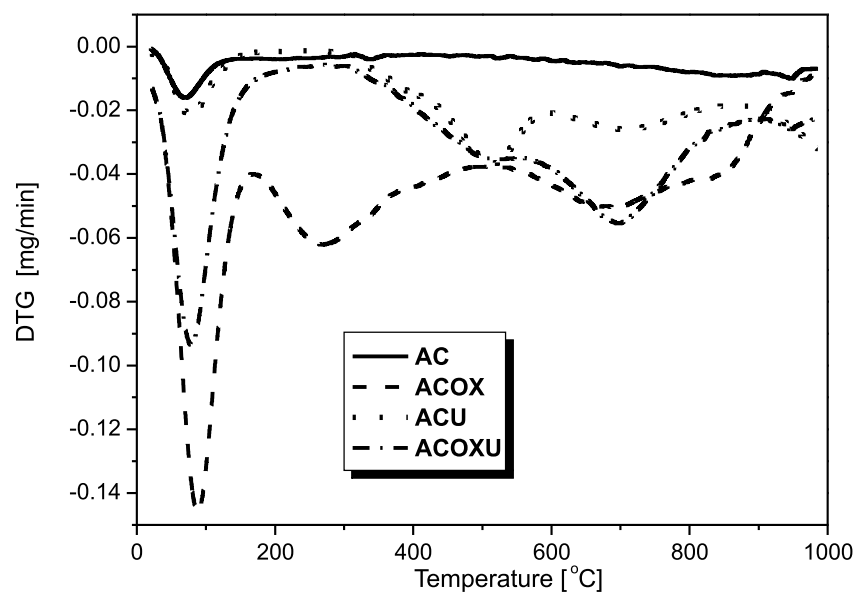

Figure 5. DTG curves of the activated carbons

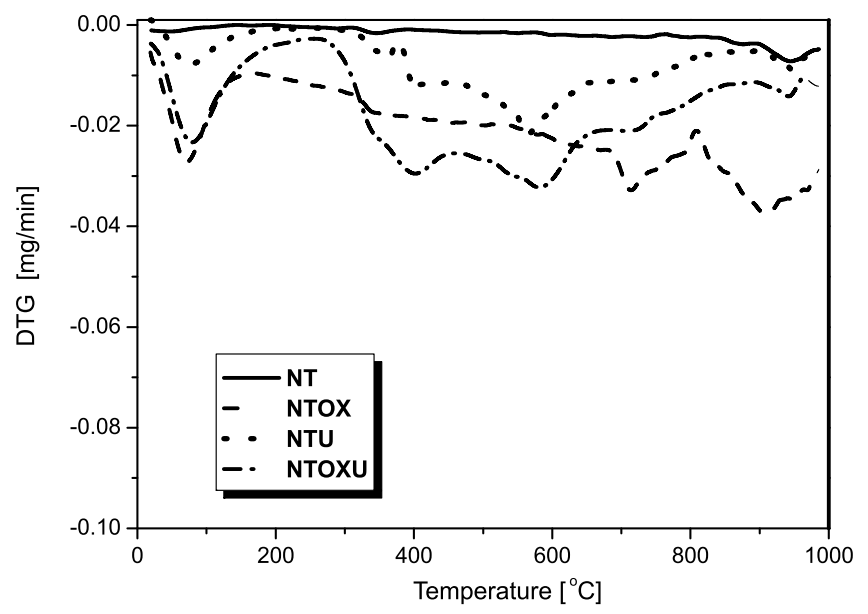

Figure 6. DTG curves of the carbon nanotubes

It is the most marked for the samples oxidised with $\mathrm{HNO}_{3}$ and for those oxidised and subjected to the reaction with urea. For ACOX and ACOXU, the depth of this minimum is much greater, fivefold and threefold, respectively, than for NTOX and NTOXU, obtained by modification of nanotubes. The presence of this minimum means that incorporation of significant amount of oxygen and to a less degree also nitrogen, causes a significant increase in the hydrophilic properties of the samples' surfaces which usually is hydrophobic ${ }^{\mathbf{3 0}}$.

As follows from the DTG curves obtained for ACU and NTU, the process of enrichment in nitrogen (without preliminary oxidation) brings about much smaller changes in hydrophilicity. Above $200^{\circ} \mathrm{C}$ the DTG curves become more diverse. The curve for ACOX reveals two broad peaks with minima at about $250-270^{\circ} \mathrm{C}$ and at $700^{\circ} \mathrm{C}$. In consistence with the earlier literature reports ${ }^{31}$, the first most probably corresponds to decomposition of poorly thermally stable oxygen groups formed as a result of the reaction with nitric(V) acid, mainly such as carboxyl and lactone groups or acidic anhydrides. The second peak can be attributed to the decomposition of more stable oxygen groups such as phenol, carbonyl, quinone and ether ones. The DTG curve recorded for the analogous sample NTOX does not show the first of the above mentioned minima, but an additional peak appears with a minimum close to $900^{\circ} \mathrm{C}$, probably corresponding to the thermal decomposition of the most stable carbonoxygen connections or pyrone structures ${ }^{32-33}$.

The character of DTG curves recorded for the nitrogenenriched samples, both with and without preceding oxidation. The DTG curve of ACOXU above $300^{\circ} \mathrm{C}$ shows a very broad peak with not much distinct minimum at about $500^{\circ} \mathrm{C}$, smoothly passing into a peak with a clear minimum at about $700^{\circ} \mathrm{C}$. The first minimum can be assigned to the decomposition of poorly thermally stable nitrogen groups such as amines, amides, imines and lactames, generated in the reaction of oxidised carbon with urea. This peak can also indicate the decomposition of nitrogen-oxygen functional groups formed upon nitrogenation. The second peak can be assigned to the decomposition of nitrogen groups in which nitrogen is built into the aromatic ring, so pyrrole, pyridone ones or pyridine $\mathrm{N}$-oxide. The DTG curve of ACU also shows these two minima, but the former is much more pronounced.

The character of DTG curves recorded for nitrogenenriched nanotubes above $200^{\circ} \mathrm{C}$ is different than that for the analogous activated carbon samples. For NTOXU, two clear minima appear at about 400 and $580^{\circ} \mathrm{C}$ together with a poorer marked one at about $700^{\circ} \mathrm{C}$, corresponding to the decomposition of nitrogen and oxygen groups generated in the reaction with urea in the oxidising conditions. For NTU an additional peak is observed with a minimum close to $380^{\circ} \mathrm{C}$. The appearance of these minima at much lower temperatures means that the groups introduced upon nitrogenation of nanotubes not only show lower thermal stability but are also much weaker bound to the carbon structure so their decomposition begins earlier. The above observations confirm that the same type modification of activated carbon and carbon nanotubes gives materials of drastically different thermal and surface properties.

\section{Sorption properties of adsorbents prepared}

To characterise the sorption abilities of activated carbon and carbon nanotube samples towards removal of organic and inorganic pollutants from liquid phase, the samples studied were tested as adsorbents of methylene blue, alkali blue 6B and copper(II) ions at room temperature. Analysis of the results presented in Table 4 proves that the modifications applied brought about different changes in the sorption properties of the materials studied.

Unfortunately, the majority of modified samples show worse sorption properties towards methylene blue and alkali blue $6 \mathrm{~B}$ than the initial materials, which may be related to the changes in their textural parameters (Table 2). Only the sample obtained by oxidation of nanotubes with $\mathrm{HNO}_{3}$ revealed improvement in the sorption properties towards the above two dyes. This result can indicate a beneficial effect of the oxygen groups generated in this process that built into the porous structure 
Table 4. Sorption properties of adsorbents prepared

\begin{tabular}{|l|c|c|c|}
\hline Sample & $\begin{array}{c}\text { Methylene blue } \\
{[\mathrm{mg} / \mathrm{g}]}\end{array}$ & $\begin{array}{c}\text { Alkali blue 6B } \\
{[\mathrm{mg} / \mathrm{g}]}\end{array}$ & $\begin{array}{c}\mathrm{Cu}^{2+} \\
{[\mathrm{mg} / \mathrm{g}]}\end{array}$ \\
\hline AC & 195 & 53 & 21 \\
\hline ACOX & 166 & 51 & 120 \\
\hline ACOXU & 120 & 49 & 151 \\
\hline ACU & 111 & 44 & 125 \\
\hline NT & 98 & 55 & 36 \\
\hline NTOX & 123 & 61 & 102 \\
\hline NTOXU & 81 & 52 & 68 \\
\hline NTU & 55 & 50 & 83 \\
\hline
\end{tabular}

of nanotubes leading to significant decrease in the pore diameter and an increase in acidity of the surface. The latter improves sorption ability towards organic dyes, especially towards the cationic methylene blue.

Unfortunately, for ACOX (after the same modification) the influence of oxygen groups was negative as the sorption properties of this sample towards both dyes were worse than those of the initial AC. The possible reasons for the different effect of the same modification on the sorption properties of nanotubes and activated carbon are the different textural parameters of the materials and first of all the dramatically different effectiveness of oxidation. The oxidation of activated carbon permits the introduction of over 4 times more oxygen groups than that of nanotubes (Table 2) and as the pores in AC are much smaller the oxygen groups could block the access to part of them by the dye molecules.

The situation is different for copper(II) ions adsorption. As follows from Table 4 data, introduction of significant amounts of oxygen and nitrogen functional groups into the carbon structure has considerably improved the effectiveness of copper(II) ions removal from water solutions. The effect is particularly pronounced for $\mathrm{AC}$ samples and the best result was an over sevenfold increase in the sorption capacity of ACOXU sample with respect to that of unmodified AC. This improvement is most probably related to the fact that copper(II) ions readily react with nitrogen and oxygen functional groups occurring together on the surface of ACOXU, which has been shown in earlier works ${ }^{34-36}$.

The sorption capacity of ACU and ACOX (subjected either only to the reaction with urea or only to oxidation with $\mathrm{HNO}_{3}$ ) is by $25-30 \mathrm{mg} / \mathrm{g}$ smaller than that of ACO$\mathrm{XU}$ but still high. These results imply that introduction of such heteroatoms as nitrogen and oxygen into the structure of adsorbents leads to an increase in the polarity of their surface and improvement of ion-exchange properties, which gives the beneficial effect of increased sorption capacity of metal cations. Modified nanotubes also revealed significant improvement in the sorption capacity but not so spectacular as that of activated carbons. The probable reason is much less amount of nitrogen and oxygen incorporated into the nanotubes structure upon their modification. Detail explanation of this problem needs further thorough studies, preceded by optimisation of the conditions of adsorption tests, the choice of the best $\mathrm{pH}$, temperature and contact time ${ }^{37-39}$.

A comparison of our experimental data with the earlier literature reports on removal of $\mathrm{Cu}^{2+}$ (Table 5) 40-49 shows that the modified carbon sorbents obtained by us (in particular those based on activated carbon) are characterised by very good sorptive properties. It is expected that careful optimisation of the modification procedures of carbon materials will lead to materials of sorption capacities and selectivity on a level close to that obtained for mesoporous silica as reported by Awual et al. ${ }^{46,49}$.

\section{CONCLUSIONS}

As follows from the above presented results, nitrogenation and oxidation of commercial adsorbents give a wide gamut of new carbon materials, differing in acid-base properties, textural parameters and at the same time showing good sorption properties towards organic dyes and copper(II) ions. The character of changes induced by the reaction with urea or by oxidation with $\mathrm{HNO}_{3}$ significantly depends on the type of material subjected to the thermo-chemical treatment. The material much more susceptible to the modifications applied was the commercially available activated carbon, as the amounts of nitrogen and oxygen functional groups incorporated in it were much greater than those incorporated to carbon nanotubes modified in the same way. The most probable reason is the greater thermal and chemical stability of nanotubes confirmed by the results of thermogravimetric measurements. The thermal analysis also proved that the functional groups introduced into the structure of the carbon materials studied, significantly reduce their thermal stability, which is particularly pronounced for activated carbons.

\section{ACKNOWLEDGEMENTS}

Financial support received from the Polish Ministry of Science and Higher Education (Project Iuventus Plus No. IP2012 004072) is gratefully acknowledged.

Table 5. Comparison of $\mathrm{Cu}(\mathrm{II})$ sorption capacity by various adsorbents

\begin{tabular}{|l|c|}
\hline Kind of adsorbent & Sorption capacity [mg/g] \\
\hline Activated carbon & $77-83$ \\
\hline Polymeric adsorbent & 74 \\
\hline Amine-grafted silica & 28 \\
\hline Ion exchange resin & 41 \\
\hline Sulfonated graphene oxide & 42 \\
\hline Modified sillica & 43 \\
\hline EBMS immobilized onto mesoporous silica monoliths & 32 \\
\hline MBHB immobilized onto mesoporous silica monoliths & 182 \\
\hline Functionalized mesoporous silica based meso-adsorbent & 44 \\
\hline HMBA embedded onto mesoporous silica monoliths & 45 \\
\hline Nitrogen-and oxygen-enriched carbonaceous adsorbents & 46 \\
\hline
\end{tabular}




\section{LITERATURE CITED}

1. Soleimani, M. \& Kaghazchi, T. (2008). Adsorption of gold ions from industrial wastewater using activated carbon derived from hard shell of apricot stones - An agricultural waste. Bioresource Technol. 99, 5374-3583. DOI: 10.1016/j. biortech.2007.11.021.

2. Soares Maia, D.A., Alexandre de Oliveira, J.C., Toso, J.P., Sapag, K., Lopez, R.H., Azevedo, D.C.S., Cavalcante Jr, C.L. \& Zgrablich, G. (2011). Characterization of the PSD of activated carbons from peach stones for separation of combustion gas mixtures. Adsorption 17, 853-861. DOI: 10.1007/ s10450-011-9344-4.

3. Tsai, W.T., Chang, C.Y., Lee, S.L. \& Wang, S.Y. (2001). Thermogravimetric analysis of corn cob impregnated with zinc chloride or preparation of activated carbon. J. Therm. Anal. Calorim. 63, 351-357. DOI: 10.1023/A:1010132207402.

4. Yagmur, E. (2012). Preparation of low cost activated carbons from various biomasses with microwave energy. $J$. Porous. Mater. 19, 995-1002. DOI: 10.1007/s10934-011-9557-7.

5. Asasian, N. \& Kaghazchi, T. (2013). A comparison on efficiency of virgin and sulfurized agro-based adsorbents for mercury removal from aqueous systems. Adsorption 19, 189-200. DOI: $10.1007 / \mathrm{s} 10450-012-9437-8$.

6. Nowicki, P., Supłat, M., Przepiórski, J. \& Pietrzak, R. (2012). $\mathrm{NO}_{2}$ removal on adsorbents obtained by pyrolysis and physical activation of corrugated cardboard. Chem. Eng. J. 195-196, 7-14. DOI: 10.1016/j.cej.2012.04.073.

7. Amaya, A., Píriz, J., Tancredi, N. \& Cordero, T. (2007). Activated carbon pellets from eucalyptus char and tar TG studies. J. Therm. Anal. Calorim. 89, 987-991. DOI: 10.1007/ s10973-006-7685-0.

8. Nowicki, P., Skibiszewska, P. \& Pietrzak, R. (2013). $\mathrm{NO}_{2}$ removal on adsorbents prepared from coffee industry waste materials. Adsorption 19, 521-528. DOI: 10.1007/s10450-0139474-y.

9. Alcañiz-Monge, J. \& Illán-Gómez, M.J. (2008). Modification of activated carbon porosity by pyrolysis under pressure of organic compounds. Adsorption 14, 93-100. DOI: 10.1007/ s10450-007-9056-y.

10. Khalil, S.H., Aroua, M.K. \& Wan Daud, W.M.A. (2012). Study on the improvement of the capacity of amine-impregnated commercial activated carbon beds for $\mathrm{CO}_{2}$ adsorbing. Chem. Eng. J. 183, 15-20. DOI: 10.1016/j.cej.2011.12.011.

11. Skubiszewska-Zięba, J., Sydorchuk, V.V., Gunko, V.M. \& Leboda, R. (2011). Hydrothermal modification of carbon adsorbents. Adsorption 17, 919-927. DOI: 10.1007/s10450-011-9369-8.

12. Budarin, V.L., Clark, J.H., Gorlova, A.A., Boldyreva, N.A. \& Yatsimirsky, V.K. (2000). Chemical modification of activated carbons. J. Therm. Anal. Calorim. 62, 349-352. DOI: $10.1023 / \mathrm{A}: 1010156002389$.

13. Tamai, H., Shiraki, K., Shiono, T. \& Yasuda, H. (2006). Surface functionalization of mesoporous and microporous activated carbons by immobilization of diamine. J. Colloid. Interf. Sci. 295, 299-302. DOI: 10.1016/j.jcis.2005.08.012.

14. Sousa, J.P.S., Pereira, M.F.R. \& Figueiredo, J.L. (2013). Modified activated carbon as catalyst for NO oxidation. Fuel Process. Technol. 106,727-733. DOI: 10.1016/j.fuproc.2012.10.008.

15. Bandosz, T.J. \& Ania, C.O. (2006). Surface chemistry of activated carbons and its characterization. In T.J. Bandosz, (ed.), Activated carbon surfaces in environmental remediation (pp. 105-229). Amsterdam, Holland: Elsevier Ltd.

16. Puziy, A.M., Poddubnaya, O.I., Gawdzik, B., Sobiesiak, M. \& Tsyba, M.M. (2007). Phosphoric acid activation-functionalization and porosity modification. Appl. Surf. Sci. 253, 5736-3740. DOI: 10.1016/j.apsusc.2006.12.034.

17. Pradhan, B.K. \& Sandle, N.K. (1999). Effect of different oxidizing agent treatments on the surface properties of activated carbon. Carbon 37, 1323-1332. DOI: 10.1016/S00086223(98)00328-5.
18. Yang, C.M. \& Kaneko, K. (2002). Adsorption properties of iodine-doped activated carbon fiber. J. Colloid. Interface. Sci. 246, 34-39. DOI: 10.1006/jcis.2001.8012.

19. Goscianska, J., Nowak, I., Nowicki, P. \& Pietrzak, R. (2012). The influence of silver on the physicochemical and catalytic properties of activated carbons. Chem. Eng. J. 189-190, 422-30. DOI: 10.1016/j.cej.2012.02.069.

20. Park, S.J. \& Shin, J.S. (2004). Preparation and characterization of activated carbon/Cu catalyst by electroless copper plating for removal of NO. J. Porous. Mater. 11, 15-19. DOI: 10.1023/B:JOPO.0000020432.04712.b8.

21. Pietrzak, R., Wachowska, H. \& Nowicki, P. (2006). Preparation of nitrogen-enriched activated carbons from brown coal. Energ. Fuel. 20, 1275-1280. DOI: 10.1021/ef0504164.

22. Nowicki, P., Pietrzak, R. \& Wachowska, H. (2009). Influence of metamorphism degree of the precursor on preparation of nitrogen enriched activated carbons by ammoxidation and chemical activation of coals. Energ. Fuel. 23, 2205-2212. DOI: $10.1021 /$ ef801094c.

23. Nowicki, P. \& Pietrzak, R. (2011). Effect of ammoxidation of activated carbons obtained from sub-bituminous coal on their $\mathrm{NO}_{2}$ sorption capacity under dry conditions. Chem. Eng. J. 166, 1039-1043. DOI: 10.1016/j.cej.2010.11.101.

24. Boehm, H.P., Diehl, E., Heck, W. \& Sappok, R. (1964). Surface oxides of carbon, Angew. Chem. Int. Ed. Engl. 3, 669-677. DOI: 10.1002/anie.196406691.

25. Kaźmierczak, J., Nowicki, P. \& Pietrzak, R. (2013). Sorption properties of activated carbons obtained from corn cobs by chemical and physical activation. Adsorption 19, 273-281. DOI: 10.1007/s10450-012-9450-y.

26. Goscianska, J., Nowak, I., Nowicki, P. \& Pietrzak, R. (2012). Thermal analysis of activated carbons modified with silver metavanadate. Thermochim. Acta 541, 42-48. DOI: 10.1016/j.tca.2012.04.026.

27. Bimer, J., Sałbut, P.D., Berłożecki, S., Boudou, J.P., Broniek, E. \& Siezieniewska, T. (1998). Modified active carbons from precursors enriched with nitrogen functions: sulfur removal capabilities. Fuel 77, 519-525. DOI: 10.1016/S00162361(97)00250-0.

28. Choma, J. \& Jaroniec, M. (2006). Characterization of nanoporous carbons by using gas adsorption isotherms. In T.J. Bandosz, (ed.), Activated carbon surfaces in environmental remediation (pp. 107-158). Amsterdam, Holland: Elsevier Ltd.

29. Biniak, S., Szymański, G., Siedlewski, J. \& Świątkowski, A. (1997). The characterization of activated carbons with oxygen and nitrogen surface groups. Carbon 35, 1799-1810. DOI:10.1016/S0008-6223(97)00096-1.

30. Bansal, R.Ch. \& Goyal, M. (2005). Activated Carbon Adsorption. Boca Raton, USA: Taylor \& Francis Group.

31. Szymański, G.S., Karpiński, Z., Biniak, S. \& Świątkowski, A. (2002). The effect of the gradual thermal decomposition of surface oxygen species on the chemical and catalytic properties of oxidized activated carbon. Carbon 40, 2627-2639. DOI: 10.1016/S0008-6223(02)00188-4.

32. Zielke, U., Huttinger, K.J. \& Hoffman, W.P. (1996). Surface-oxidized carbon fibres: I. surface structure and chemistry. Carbon 34, 983-998. DOI: 10.1016/0008-6223(96)00032-2.

33. Barton, S.S., Evans, M.I.B., Halliop, E. \& MacDonald, J.A.F. (1997). Anodic oxidation of porous carbon. Langmuir 13, 1332-1336. DOI: 10.1021/la9509413.

34. Biniak, S., Pakuła, M. \& Świątkowski, A. (2001). Electrochemical studies of phenomena at active carbon-electrolyte solution interfaces. In L.R. Radovic, (ed.). Chemsitry and physics of carbon (pp. 125-226). New York, USA: Marcel Dekker,

35. Bandosz, T.J. (2009). Surface chemistry of carbon materials. In F. Serp \& J.L. Figueiredo (eds.) Carbon materials for catalysis (pp. 45-92). Hoboken, USA: John Wiley \& Sons Inc.

36. Boehm, H.P. (2008). Surface chemical characterization of carbons from adsorption studies. In E.J. Bottani \& J.M.D. 
Tascon (eds.) Adsorption by carbons (pp. 301-328). Oxford, England: Elsevier.

37. Awual, M.R. (2015). A novel facial composite adsorbent for enhanced copper(II) detection and removal from wastewater. Chem. Eng. J. 266, 368-375. DOI:10.1016/j.cej.2014.12.094.

38. Awual, M.R. \& Hasan, M.M. (2015). Colorimetric detection and removal of copper(II) ions from wastewater samples using tailor-made composite adsorbent. Sensor. Actuat. B-Chem. 206, 692-700. DOI:10.1016/j.snb.2014.09.086.

39. Awual, M.R., Yaita, T. \& Okamoto, Y. (2014). A novel ligand based dual conjugate adsorbent for cobalt(II) andcopper(II) ions capturing from water. Sensor. Actuat. B-Chem. 203, 71-80. DOI:10.1016/j.snb.2014.06.088.

40. Rio, S., Faur-Brasquet, C., Coq, L.L., Courcoux, P. \& Cloirec, P.L. (2005). Experimental design methodology for the preparation of carbonaceous sorbents from sewage sludge by chemical activation - application to air and water treatments. Chemosphere 58, 423-427. DOI: 10.1016/j.chemosphere.2004.06.003.

41. Liu, C., Bai, R. \& Ly, Q.S. (2008). Selective removal of copper and lead ions by diethylenetriamine-functionalized adsorbent: Behaviors and mechanisms. Water Res. 42, 1511-1522. DOI: 10.1016/j.watres.2007.10.031.

42. Liu, A.M., Hidajat, K., Kawi, S. \& Zhao, D.Y. (2000). A new class of hybrid mesoporous materials with functionalized organic monolayers for selective adsorption of heavy metal ions. Chem. Commun. 1145-1146. DOI: 10.1039/B002661L.

43. Cochrane, E.L., Lu, S., Gibb, S.W. \& Villaescusa, I. (2006) A comparison of low-cost biosorbents and commercial sorbents for the removal of copper from aqueous media. J. Hazard. Mater. 137, 198-206. DOI: 10.1016/j.jhazmat.2006.01.054.

44. Hu, X., Liu, Y., Wang, H., Chen, A., Zeng, G., Liu, S., Guo, Y., Hu, X., Li, T., Wang, L., Zhou, L. \& Liu, S. (2013). Removal of $\mathrm{Cu}(\mathrm{II})$ ions from aqueous solution using sulfonated magnetic graphene oxide composite. Sep. Purif. Technol. 108, 189-195. DOI: 10.1016/j.seppur.2013.02.011.

45. Bois, L., Bonhomme, A., Ribes, A., Pais B., Fraffin, G. \& Tessier, F. (2003). Functionalized silica for heavy metal ions adsorption. Colloid. Surf. A: Physicochem. Eng. Asp. 221, 221-230. DOI: 10.1016/S0927-7757(03)00138-9.

46. Awual, M.R., Ismael, M., Yaita, T., El-Safty, S.A., Shiwaku, H., Okamoto, Y. \& Suzuki, S. (2013). Trace copper(II) ions detection and removal from water using novel ligand modified composite adsorbent. Chem. Eng. J. 222, 67-76. DOI: 10.1016/j.cej.2013.02.042.

47. Awual, M.R., Yaita, T., El-Safty, S.A., Shiwaku, H., Suzuki, S. \& Okamoto, Y. (2013). Copper(II) ions capturing from water using ligand modified a new type mesoporous adsorbent. Chem. Eng. J. 221, 322-330. DOI: 10.1016/j.cej.2013.02.016.

48. Awual, M.R., Ismael, M., Khaleque, M.A. \& Yaita, T. (2014). Ultra-trace copper(II) detection and removal from wastewater using novel meso-adsorbent. J. Ind. Eng. Chem. 20, 2332-2340. DOI: 10.1016/j.jiec.2013.10.009.

49. Awual, M.R., Rahman, I.M.M., Yaita, T., Khaleque, M.A. \& Ferdows, M. (2014). pH dependent $\mathrm{Cu}$ (II) and $\mathrm{Pd}(\mathrm{II})$ ions detection and removal from aqueous media by an efficient mesoporous adsorbent. Chem. Eng. J. 236, 100-109. DOI: 10.1016/j.cej.2013.09.083. 